\title{
Genome-wide association study with imputed whole-genome sequence variants including large deletions for female fertility in 3 Nordic dairy cattle breeds
}

\author{
Md Mesbah-Uddin, ${ }^{1,2 *} \odot$ Bernt Guldbrandtsen, ${ }^{1} \dagger \odot$ Aurélien Capitan, ${ }^{2,3} \odot$ Mogens Sandø Lund, ${ }^{1}$ \\ Didier Boichard, ${ }^{2}$ and Goutam Sahana ${ }^{1} \ddagger \mathbb{0}$ \\ ${ }^{1}$ Center for Quantitative Genetics and Genomics, Aarhus University, 8830 Tjele, Denmark \\ ${ }^{2}$ Génétique Animale et Biologie Intégrative (GABI), Institut national de recherche pour l'agriculture, l'alimentation et l'environnement (INRAE), \\ AgroParisTech, Université Paris-Saclay, 78350 Jouy-en-Josas, France \\ ${ }^{3}$ Allice, 75595 Paris, France
}

\begin{abstract}
Fertility is an economically important trait in livestock. Poor fertility in dairy cattle can be due to lossof-function variants affecting any essential gene that causes early embryonic mortality in homozygotes. To identify fertility-associated quantitative trait loci, we performed single-marker association analyses for 8 fertility traits in Holstein, Jersey, and Nordic Red Dairy cattle using imputed whole-genome sequence variants including SNPs, indels, and large deletion. We then performed stepwise selection of independent markers from GWAS loci using conditional and joint association analyses. From single-marker analyses for fertility traits, we reported genome-wide significant associations of 30,384 SNPs, 178 indels, and 3 deletions in Holstein; 23,481 SNPs, 189 indels, and 13 deletions in Nordic Red; and 17 SNPs in Jersey cattle. Conditional and joint association analyses identified 37 and 23 independent associations in Holstein and Nordic Red Dairy cattle, respectively. Fertility-associated GWAS loci were enriched for developmental and cellular processes (Gene Ontology enrichment, false discovery rate $<0.05$ ). For these quantitative trait loci regions (top marker and 500 $\mathrm{kb}$ of surrounding regions), we proposed several candidate genes with functional annotations corresponding to embryonic lethality and various fertility-related phenotypes in mouse and cattle. The inclusion of these top markers in future releases of the custom SNP chip used for genomic evaluations will enable their validation in

Received April 24, 2021

Accepted September 22, 2021.

*Current address: Natarajan Lab, Medical and Population Genetics Broad Institute of MIT and Harvard, Cambridge, MA 02142.

†Current address: Department of Veterinary and Animal Sciences, University of Copenhagen, Frederiksberg C 1870, Denmark.

‡Corresponding author: goutam.sahana@qgg.au.dk
\end{abstract}

independent populations and improve the accuracy of genomic predictions.

Key words: genome-wide association study, fertility, deletion, dairy cattle

\section{INTRODUCTION}

Over the years, GWAS have provided a better understanding of underlying genetic architectures for many economical traits in dairy cattle. These traits include milk yield (Iso-Touru et al., 2016), milk composition (Gebreyesus et al., 2019; Sanchez et al., 2019), milking speed (Jardim et al., 2018; Marete et al., 2018), clinical mastitis (Kadri et al., 2015; Cai et al., 2018), body conformation (Abo-Ismail et al., 2017), stature (Bouwman et al., 2018), and more. Female fertility is an economically important trait, which, before the advent of genomic selection, was difficult to improve by selection due to its very low heritability. The use of GWAS for female fertility provided an opportunity to detect QTL (Höglund et al., 2014, 2015a,b) and to include these QTL in genomic prediction (Brøndum et al., 2015).

However, the accuracy of prediction for female fertility is lower compared with production traits (Brøndum et al., 2015). There is a potential to identify QTL or markers in strong linkage disequilibrium (LD) with QTL using GWAS for female fertility to use the QTL information in breeding value prediction. Two ways to increase the power of GWAS in mapping populations of fixed size are (1) to consider additional classes of genetic variants in addition to SNPs such as small indels and various types of structural variations, and (2) to impute SNP chip genotyping data to the whole-genome sequence.

As for structural variants, particularly large chromosomal deletions (e.g., >50 bp in size) are potential candidates for loss of function where deletion of an essential gene or part of it could be lethal and cause 
embryonic mortality in homozygotes. Known causal deletions include FANCI deletion causing brachyspina in Holstein (Charlier et al., 2012), RNASEH2B deletion causing embryonic lethality (Kadri et al., 2014), and a $\sim 525$-kb deletion (encompassing BTBD9, GLO1, and $D N A H 8$ ) responsible for stillbirth (Sahana et al., 2016; Mesbah-Uddin et al., 2018) in Nordic Red cattle. Furthermore, deletions in cattle were also enriched for health- and fertility-related QTL in Cattle QTLdb $\mathrm{Hu}$ et al., 2016; Mesbah-Uddin et al., 2018), which underscore the functional and biological relevance of these variants in fitness-related traits.

To include deletions in addition to SNPs and indels in gene mapping and prediction of breeding values in cattle, we previously performed genome-wide mapping of deletions in 175 whole-genome sequence (WGS) animals, 67 Holstein (HOL), 81 Nordic Red (RDC), and 27 Jersey (JER) cattle, and identified $\sim 8,500$ variants ranging from $199 \mathrm{bp}$ to $773 \mathrm{~kb}$ in size (Mesbah-Uddin et al., 2018). Later, we imputed these deletions along with WGS SNPs and indels, with an average imputation accuracy squared Pearson correlation $\left(r^{2}\right)>0.9$, in a cohort of 13,000 bulls from HOL, RDC, and JER genotyped using medium- and high-density SNP array chip (Mesbah-Uddin et al., 2019). In this study, we performed GWAS for 8 fertility traits in HOL, RDC, and JER using imputed WGS variants including SNPs, indels, and deletions. We hypothesized that inclusion of indels and large deletions in addition to whole-genome single nucleotide variants could identify candidate genes for female fertility traits in dairy cattle.

\section{METHODS}

No animal handling or animal experiment was conducted for this study; therefore, approval from institutional animal care and use was not necessary.

\section{Genotypes and Phenotypes}

In an earlier study, using a multibreed WGS reference panel of 772 animals that included $548 \mathrm{HOL}, 132 \mathrm{RDC}$, and 92 JER animals, we performed imputation from the Illumina BovineSNP50 (50k) to WGS SNPs, small indels, and deletions in a cohort of $\sim 13,000$ bulls $[6,371$ HOL, 4,955 RDC, and 1,640 JER; for details see Mesbah-Uddin et al. $(2018,2019)]$. In short, for the imputation reference panel, SNPs and indels were identified from 175 WGS samples from the Nordic sequence data (Brøndum et al., 2014) and 597 WGS samples from the Run-6 of the 1000 Bull Genomes Project (Daetwyler et al., 2014) using the GATK v1.6 (McKenna et al., 2010) and SAMtools 0.1.18 mpileup (Li et al., 2009) software, respectively. Additionally, chromosomal deletions (199 bp-773 kb) were mapped and genotyped in the 175 Nordic WGS samples (Mesbah-Uddin et al., 2018) using Genome STRiP software v2.00.1678 (Handsaker et al., 2011). Subsequently, deletion genotyping was extended to the remaining 597 WGS samples of the reference panel using the read-depth data from the variant call format file in a Gaussian mixture model-based genotyping approach (Mesbah-Uddin et al., 2019).

Imputation was performed in 2 steps using the multibreed reference panel. First, we imputed 9,932 animals $(5,371 \mathrm{HOL}, 3,723 \mathrm{RDC}$, and $838 \mathrm{JER})$ from the $50 \mathrm{k}$ genotypes to the BovineHD BedChip genotypes (777k) using a $777 \mathrm{k}$ haplotype reference panel of 3,375 animals (1,215 HOL, 1,325 RDC, and 835 JER). Second, using the multibreed WGS reference panel, the target $\sim 13 \mathrm{k}$ samples were imputed from the $777 \mathrm{k}$ genotypes to WGS SNPs, small indels, and deletions. Here, genotype phasing was performed using a combination of Beagle v4.r1274 (Browning and Browning, 2016) and SHAPEIT v2.r837 software (Delaneau et al., 2013, 2014). Imputation was performed using Minimac3 v.2.0.1 (Das et al., 2016). Overall, average imputation accuracies (Minimac $r^{2}$ ) were 0.93 for SNPs, 0.90 for small indels, and 0.90 for deletions (Mesbah-Uddin et al., 2019). In this study, we used the imputed WGS data set of $13 \mathrm{k}$ animals to perform GWAS for female fertility in HOL, RDC, and JER (Table 1).

From the above-mentioned imputation data set (which had several filters for low quality markers including deviation from Hardy-Weinberg proportion, $P$ $\leq 1 \times 10^{-5}$ ), we considered markers with minor allele frequency $>1 \%$ and Minimac $r^{2}$ value $\geq 0.1$ for GWAS. At this minor allele frequency and Minimac $r^{2}$, the genotype data set comprised 12,174,287 markers in HOL (12,076,004 SNPs; 94,581 indels; 3,702 deletions), $12,855,372$ markers in RDC $(12,748,285$ SNPs, 102,843 indels, 4,244 deletions), and 10,135,228 markers in JER (10,057,293 SNPs; 74,829 indels; 3,106 deletions).

The phenotypic data in each breed were deregressed breeding values of AI bulls (VanRaden and Wiggans, 1991; Garrick et al., 2009) for 8 fertility traits as follows: number of inseminations per conception in heifers, number of inseminations per conception in cows (AISc), interval (number of days) from calving to first insemination in cows (ICF), interval (number of days) from first to last insemination in heifers, interval from first to last insemination in cows (IFLc), fertility index (FI), nonreturn rate in heifers, and nonreturn rate in cows (NRRc); for details, see NAV (2013). Deregressed proofs are a proxy of the average performance of bulls' daughters, adjusted for nongenetic effects and breeding values of their dams. Summary of these phenotypes 


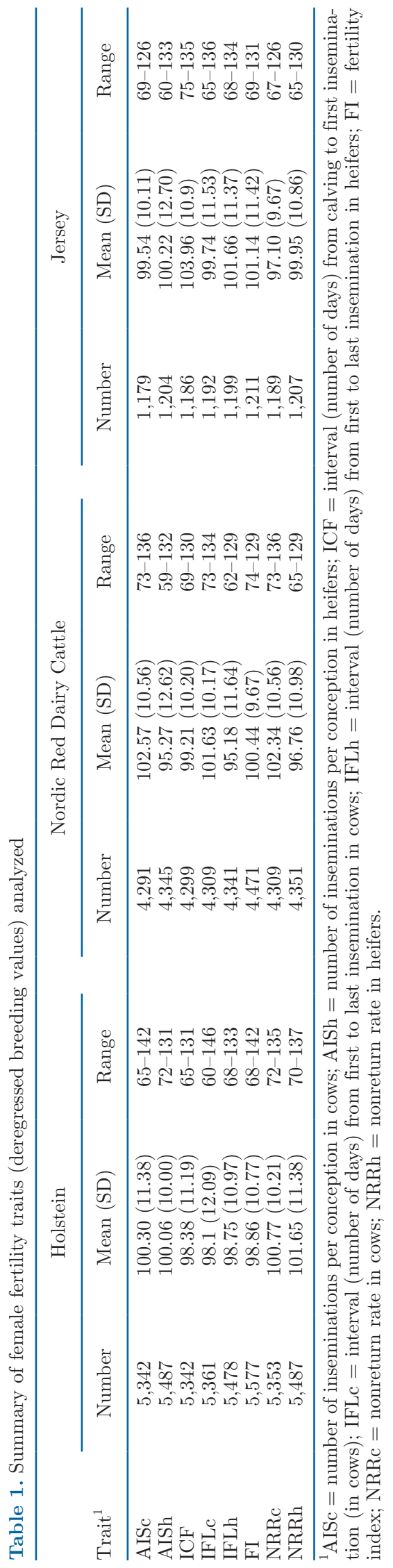

was presented in Table 1. The final data set included phenotypes (breeding values) and imputed genotypes for 5,596 HOL, 4,507 RDC, and 1,215 JER bulls.

\section{Genome-Wide Association Study}

We performed single-marker association analyses using the following mixed linear model:

$$
\mathbf{y}=\mathbf{1}_{n} \mu+b \mathbf{x}+\sum_{i=1}^{10} c_{i} \mathbf{P C}_{i}+\mathbf{g}+\varepsilon
$$

where $\mathbf{y}$ was a vector of phenotypic records for fertility traits; $\mathbf{1}_{n}$ was a vector of ones; $\mu$ was the mean of the given trait; $b$ was the additive allele substitution effect of the candidate marker to be tested; $\mathbf{x}$ was a vector of allele dosages (coded as 0,1 , or 2), $\mathbf{P} \mathbf{C}_{i}$ was a vector of animals' scores for principal components of genetic ancestry $i$ [first 10 principal components (PC) were considered, calculated from a random set of $10 \%$ markers selected from the 29 autosomes]; $c_{i}$ was the regression coefficient for score $i$; $\mathbf{g}$ was a vector of polygenic effects with $\boldsymbol{g} \sim N\left(0, \mathbf{G} \sigma_{g}^{2}\right)$, where $\mathbf{G}$ was the genomic relationship matrix calculated using the $777 \mathrm{k}$ markers without the test chromosome [leave-one-chromosome-out (LOCO) approach]; $\sigma_{g}^{2}$ was the additive genetic variance explained by the $777 \mathrm{k}$ markers in LOCO approach; $\varepsilon$ was the vector of residual effect with $\varepsilon \sim N\left(0, \mathbf{I} \sigma_{\varepsilon}^{2}\right)$, where $\mathbf{I}$ was an $n \times n$ identity matrix and $\sigma_{\varepsilon}^{2}$ was the residual variance. Differences in reliabilities of deregressed proofs were ignored as we used deregressed breeding values from progeny-tested bulls. The analysis was performed using GCTA version 1.92.1 (Yang et al., 2011a). Any association with the trait of interest was considered statistically significant at $P<5 \times 10^{-8}$, considering 1 million independent tests at $5 \%$ level of significance.

We estimated the genomic inflation factor, $\lambda$, for the set of single-marker GWAS $P$-values using "median(qchisq(1 - $\mathbf{P}, 1)$ )/qchisq(0.5,1)" in R (R v4.0; cran.r-project.org), where $\mathbf{P}$ is a vector of GWAS $P$ values.

\section{Conditional and Joint Association Analysis}

Next, to refine the analysis within each QTL region and account for LD, we performed stepwise model selection using genome-wide complex trait analysis (GCTA)-conditional and joint association analysis (COJO) (Yang et al., 2012). For each chromosome, from the single-marker associations at $P<5 \times 10^{-8}$, we selected the marker with lowest association $P$-value 
(top marker) and reran the GWAS for the chromosome including the genotype of the top marker and first 10 $\mathrm{PC}$ as fixed effects, and the LOCO-genomic relationship matrix as random effect. We used an LD threshold of 0.80 to identify independent marker(s) and assumed complete independence for markers at least $10 \mathrm{Mb}$ away from a conditional marker. After each iteration, the marker with lowest $P$-value was selected when it was below the GWAS threshold of $5 \times 10^{-8}$ and was added to the conditional marker list for the next iteration. When there were multiple markers with same (lowest) $P$-value, the first marker based on chromosome position was arbitrarily chosen. Finally, for each chromosome, all selected markers on the chromosome were fitted simultaneously.

\section{Annotation and Enrichment Analysis}

We used the Bos taurus reference genome assembly UMD3.1 (Zimin et al., 2009; Elsik et al., 2016) throughout this study. To identify candidate genes within a QTL, we used the Ensembl (release 94) database (https://ftp.ensembl.org/pub/release-94; Zerbino et al., 2018) and manually inspected $1 \mathrm{Mb}$ genomic region centered on the top marker (i.e., top marker $500 \mathrm{~kb}$ of the surrounding region). From Ensembl, we retrieved annotations for genes and known phenotypes associated with those genes. However, when multiple genes were located within an interval, for reporting, we prioritized genes with records of fertility- and fitnessrelated phenotypes in Online Mendelian Inheritance in Animals (OMIA; www.omia.org), Online Mendelian Inheritance in Man (OMIM; https://www.omim.org/), mouse (http://www.informatics.jax.org/ and https:// www.mousephenotype.org/), and rat (https://rgd.mcw .edu/wg/).

The Gene Ontology (GO) analysis was performed for FI-associated variants at $P<5 \times 10^{-8}$ in HOL, or RDC, or nominally associated at $P<5 \times 10^{-5}$ in JER. We extracted genes within $500 \mathrm{~kb}$ upstream and $500 \mathrm{~kb}$ downstream of the FI-associated variants from Ensembl UMD3.1 gene annotation (http://ftp.ensembl.org/ pub/release-94/gtf/bos_taurus/Bos_taurus.UMD3.1 .94.chr.gtf.gz). The g:Profiler web server (Raudvere et al., 2019) was used for GO enrichment analysis, and GO terms at false discovery rate $<0.05$ were reported.

Additionally, we also used $\mathrm{R}$ base package (v4.0.2), qqman (Turner, 2018), ggplot2, and VennDiagram (Chen and Boutros, 2011) for plotting.

\section{RESULTS AND DISCUSSION}

We performed single-marker association analysis for 8 female fertility traits (Table 1) in HOL, RDC, and
JER cattle using imputed WGS SNPs, indels, and deletions. The GWAS Manhattan plots for 8 traits in the 3 breeds are presented in Figures 1, 2, and 3, and the summary of variants that reached genome-wide significant threshold of $P<5 \times 10^{-8}$ is presented in Table 2 .

Association test statistics were inflated when we only accounted for relatedness using the genomic relationship matrix derived from the $777 \mathrm{k}$ markers in a LOCO approach (Table 3). Therefore, following Jiang et al. (2019), we adjusted for both population stratification using the first $10 \mathrm{PC}$ as fixed effects, and relationships among animals using the LOCO approach. Genomic inflation rates $(\lambda)$ before and after fitting the $\mathrm{PC}$ are presented in Table 3 . We observed a decrease in $\lambda$ values after the inclusion of PC as covariates, although $\lambda$ was still very far from 1 under the assumption of the distribution of test statistics under the null hypothesis. However, when a trait is under polygenic inheritance [i.e., multiple (small effect) causal variants underlie the trait variation (also known as infinitesimal model)], a substantial inflation of GWAS test statistics is expected even in the absence of population structure (Yang et al., 2011b). The extent of this inflation is governed by several factors, namely, heritability of the trait, study sample size, pattern of LD, and number of causal variants [for detail, see Yang et al. (2011b)]. The genomic inflation seen in this study despite the correction for population stratification and relatedness could be explained by the nature of polygenic inheritance of the fertility traits we analyzed (e.g., several nonzero effect genetic variants in Bayesian mixture models as reported by Brøndum et al., 2015). The phenotypes used here are deregressed breeding values for bulls with high reliability. The long-range LD pattern seen in the study population (de Roos et al., 2008; van den Berg et al., 2016) could also explain inflation of $\lambda$ values observed in this study. Among the 3 breeds, HOL had the largest sample size, and thus the highest power to identify QTL; we also observed the highest $\lambda$ values in HOL. However, the adjustment for both population stratification and relatedness could be very conservative; nonetheless, we expect that the test statistics will be robust against spurious associations and false discoveries (Jiang et al., 2019).

\section{Fertility-Associated Loci Are Enriched for GO Terms Related to Cellular and Developmental Processes}

We performed GO enrichment using genes within a 500-kb surrounding area of FI-associated loci in HOL, RDC, and JER. Interestingly, only 22 genes (within chromosome 13: 51-55 mb) were common among the 3 breeds (Figure 4a). Despite limited overlap, gene-set enrichment analysis showed that genes near the FI- 

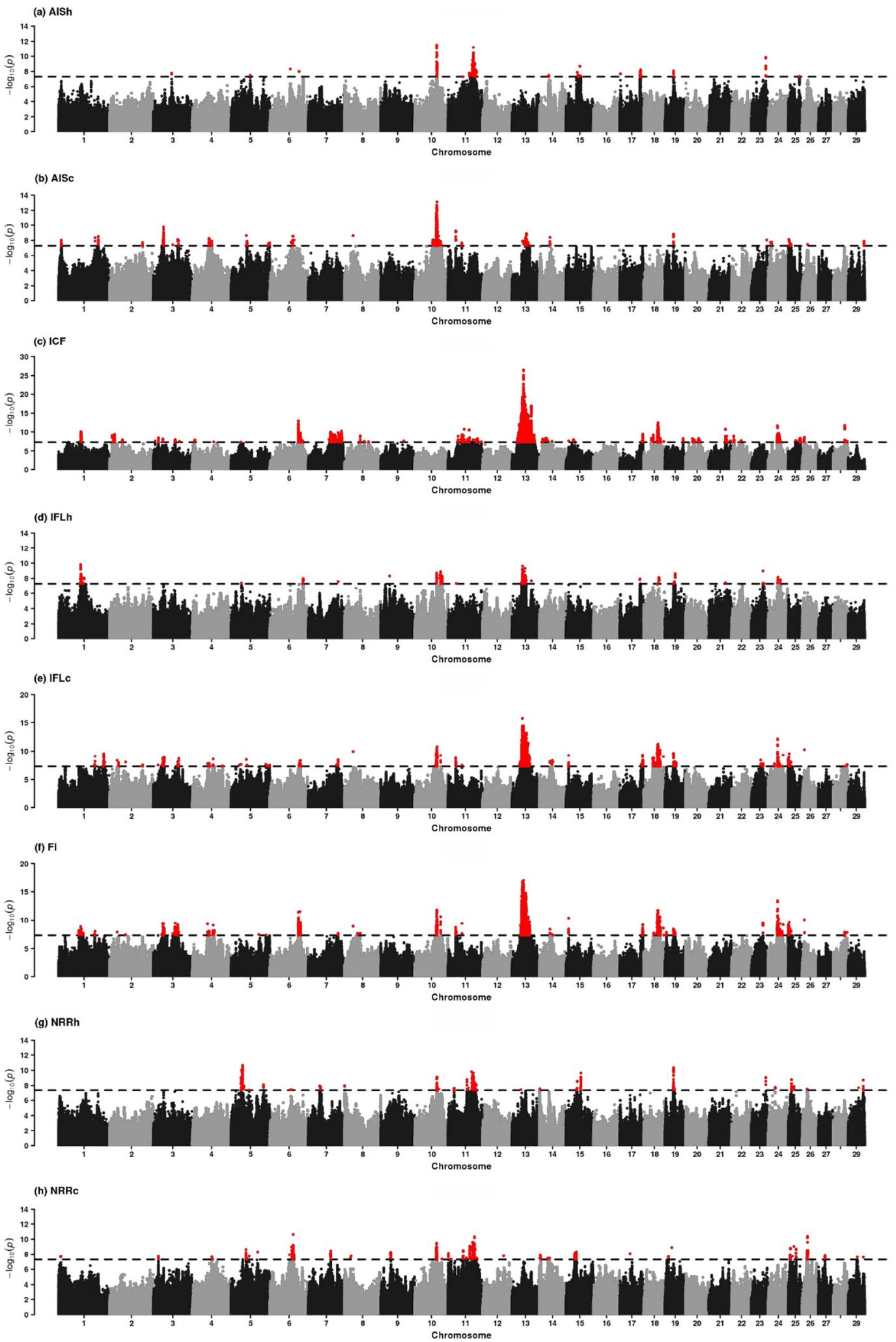

Figure 1. Manhattan plots of single-marker GWAS for 8 female fertility traits in Holstein cattle. Each dot represents 1 whole-genome sequence (WGS) marker; dashed horizontal line is GWAS threshold of $5 \times 10^{-8}$. AISh $=$ number of inseminations per conception in heifers; AISc $=$ number of inseminations per conception in cows; ICF $=$ interval (number of days) from calving to first insemination (in cows); IFLh $=$ interval (number of days) from first to last insemination in heifers; IFLc $=$ interval (number of days) from first to last insemination in cows; FI $=$ fertility index; $\mathrm{NRRh}=$ nonreturn rate in heifers; $\mathrm{NRRc}=$ nonreturn rate in cows 

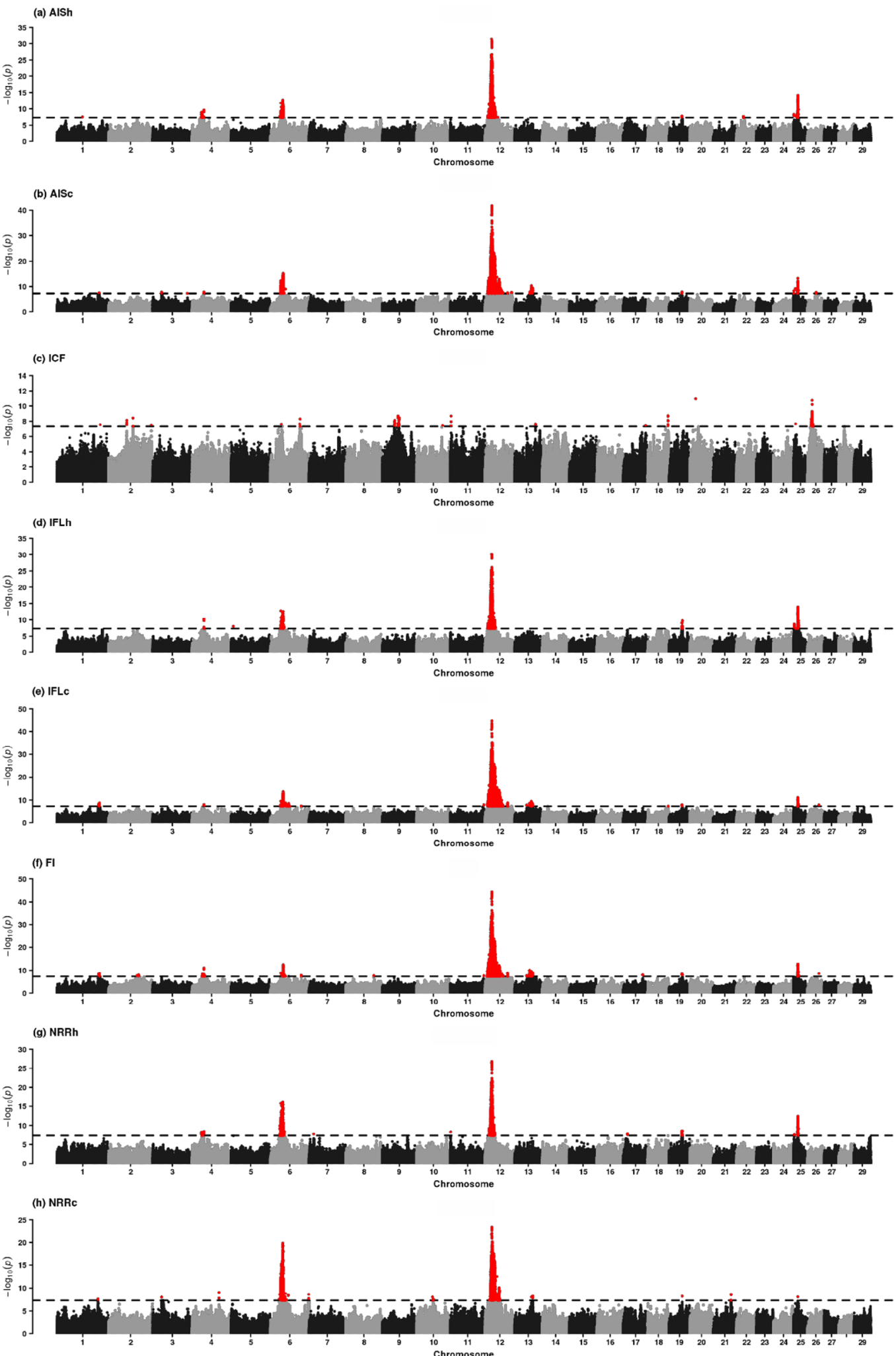

Figure 2. Manhattan plots of single-marker GWAS for 8 female fertility traits in Nordic Red Dairy cattle. Each dot represents 1 wholegenome sequence (WGS) marker; dashed horizontal line is GWAS threshold of $5 \times 10^{-8}$. AISh $=$ number of inseminations per conception in heifers; AISc $=$ number of inseminations per conception in cows; ICF $=$ interval (number of days) from calving to first insemination (in cows); IFLh $=$ interval (number of days) from first to last insemination in heifers; IFLc $=$ interval (number of days) from first to last insemination in cows; FI $=$ fertility index; NRRh $=$ nonreturn rate in heifers; NRRc $=$ nonreturn rate in cows. 

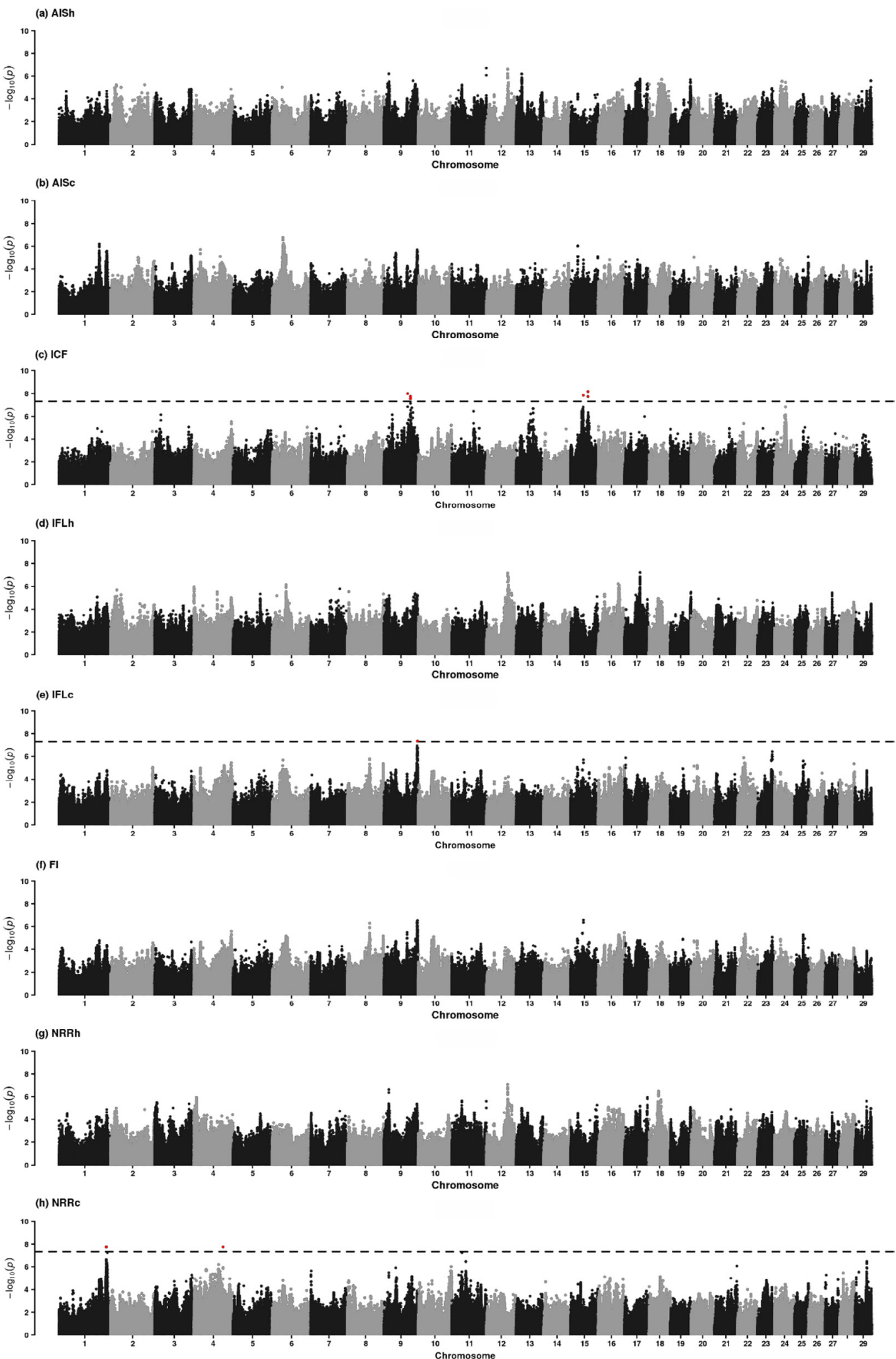

Figure 3. Manhattan plots of single-marker GWAS for 8 female fertility traits in Jersey cattle. Each dot represents 1 whole-genome sequence (WGS) marker; dashed horizontal line is GWAS threshold of $5 \times 10^{-8}$. AISh $=$ number of inseminations per conception in heifers; AISc $=$ number of inseminations per conception in cows; ICF = interval (number of days) from calving to first insemination (in cows); IFLh $=$ interval (number of days) from first to last insemination in heifers; IFLc = interval (number of days) from first to last insemination in cows; FI $=$ fertility index; $\mathrm{NRRh}=$ nonreturn rate in heifers; $\mathrm{NRRc}=$ nonreturn rate in cows 
Table 2. Summary of single-marker association results (markers with $P$-value $\left.<5 \times 10^{-8}\right)$

\begin{tabular}{lrcc}
\hline Trait $^{1}$ & Holstein & $\begin{array}{c}\text { Nordic Red } \\
\text { Dairy Cattle }\end{array}$ & Jersey \\
\hline AISh & 583 & 10,004 & 0 \\
AISc & 2,012 & 16,089 & 0 \\
ICF & 21,539 & 280 & 8 \\
IFLh & 932 & 7,302 & 0 \\
IFLc & 7,645 & 16,289 & 1 \\
FI & 11,091 & 14,916 & 0 \\
NRRh & 1,057 & 8,036 & 0 \\
NRRc & 2,008 & 9,182 & 8 \\
\hline
\end{tabular}

${ }^{1} \mathrm{AISh}=$ number of inseminations per conception in heifers; AISc $=$ number of inseminations per conception in cows; ICF = interval (number of days) from calving to first insemination (in cows); IFLh $=$ interval (number of days) from first to last insemination in heifers; IFLc $=$ interval (number of days) from first to last insemination in cows; FI = fertility index; NRRh $=$ nonreturn rate in heifers; NRRc $=$ nonreturn rate in cows.

associated GWAS loci are enriched for developmental and cellular processes (false discovery rate $<0.05$ ) in HOL, RDC, and JER (Figure 4b-d). Furthermore, majority of the GO enrichments were in similar molecular, cellular, and biological processes in the 3 breeds (Supplemental Tables S1-S3; https://doi.org/10.6084/m9 .figshare.16910521.v2; Mesbah-Uddin, 2021). Although our GWAS was underpowered, especially for JER, this GO enrichment highlighted that common biological pathways may be involved in female fertility in dairy cattle. This pathway sharing across-breeds showed that there is a potential to use multibreed reference in predicting fertility in dairy cattle, where substantial gains in accuracy could be achieved for breeds with numerically small reference populations.

\section{Deletions Associated With Female Fertility Traits}

In HOL, 3 deletions were significantly associated $(P$ $<5 \times 10^{-8}$ ) with ICF, FI, and NRRc (Table 4$)$. We identified 3 candidate genes, ACSS1, CFAP61, and
HELLS, within $500 \mathrm{~kb}$ upstream and $500 \mathrm{~kb}$ downstream of these deletions, that are known to be associated with embryonic lethality, premature death, and male infertility in mouse (Supplemental Table S4; https://doi.org/10.6084/m9.figshare.16910521.v2; Mesbah-Uddin, 2021). A recent study also showed that CFAP61 plays a vital role in male fertility in humans (Liu et al., 2021).

In RDC, 13 deletions reached genome-wide significance; associated phenotypes included 7 fertility traits (Table 4). The strongest association was observed for a previously known lethal deletion on chromosome 12 located between position 20,100,648 and 20,763,119 bp (structural variant id esv4015629, $P=3.5 \times 10^{-42}$ ). We found that esv 4015629 was significantly associated with 7 fertility traits, in agreement with results reported by Kadri et al. (2014). However, we did not find any association between esv4015629 and ICF. It is worth mentioning that ICF is related to estrous cycle (prepregnancy), and thus is not affected by early embryo losses, whereas the 7 other associated traits are related to pregnancy success. Several traits had multiple associated deletions. Three traits, FI, IFLc, and AISc, had strong genetic correlations (correlation of 0.98 between FI vs. IFLc, and 0.89 between FI vs. AISc). They shared associations with 7 deletions (Table 4). Several genes within these deletions have known fertility-related phenotypes, including embryonic lethality in mice (Supplemental Table S4).

However, no deletion reached genome-wide significance for female fertility traits in JER. The top 5 associations included esv4014584 [chromosome (Chr) 13:50,733,796-50,735,009; associated with ICF, $\left.P=3.2 \times 10^{-6}\right]$, esv4018559 (Chr6:33,504,998-33,506 , 227 ; associated with AISc, $\left.P=3.4 \times 10^{-6}\right)$, esv4019122 (Chr6:33,738,269-33,738,743; associated with AISc, $\left.P=3.4 \times 10^{-6}\right), \operatorname{esv} 4017388(\mathrm{Chr} 1: 145,570,019-145$ $, 570,346$; associated with NRRc, $\left.P=8.5 \times 10^{-6}\right)$, and esv4017421 (Chr3:7,140,763-7,141,120; associated with

Table 3. Genomic inflation rate, $\lambda$, before and after correcting for population stratification using first 10 principal components (PC)

\begin{tabular}{|c|c|c|c|c|c|c|}
\hline \multirow[b]{2}{*}{ Trait $^{1}$} & \multicolumn{2}{|c|}{ Holstein } & \multicolumn{2}{|c|}{ Nordic Red Dairy Cattle } & \multicolumn{2}{|c|}{ Jersey } \\
\hline & Without PC & With PC & Without PC & With PC & Without PC & With PC \\
\hline$\overline{\mathrm{AISh}}$ & 1.76 & 1.65 & 1.41 & 1.37 & 1.39 & 1.29 \\
\hline AISc & 2.04 & 1.83 & 1.56 & 1.50 & 1.31 & 1.24 \\
\hline ICF & 2.38 & 2.19 & 1.63 & 1.57 & 1.36 & 1.29 \\
\hline IFLh & 1.93 & 1.81 & 1.42 & 1.37 & 1.37 & 1.29 \\
\hline IFLc & 2.24 & 2.02 & 1.59 & 1.53 & 1.32 & 1.25 \\
\hline FI & 2.26 & 2.05 & 1.59 & 1.52 & 1.33 & 1.27 \\
\hline NRRh & 1.99 & 1.84 & 1.41 & 1.38 & 1.37 & 1.29 \\
\hline NRRc & 2.20 & 1.98 & 1.53 & 1.48 & 1.39 & 1.28 \\
\hline
\end{tabular}

${ }^{1} \mathrm{AISh}=$ number of inseminations per conception in heifers; AISc $=$ number of inseminations per conception in cows; ICF $=$ interval $($ number of days) from calving to first insemination (in cows); IFLh $=$ interval (number of days) from first to last insemination in heifers; IFLc $=$ interval (number of days) from first to last insemination in cows; FI = fertility index; NRRh = nonreturn rate in heifers; NRRc = nonreturn rate in cows. 

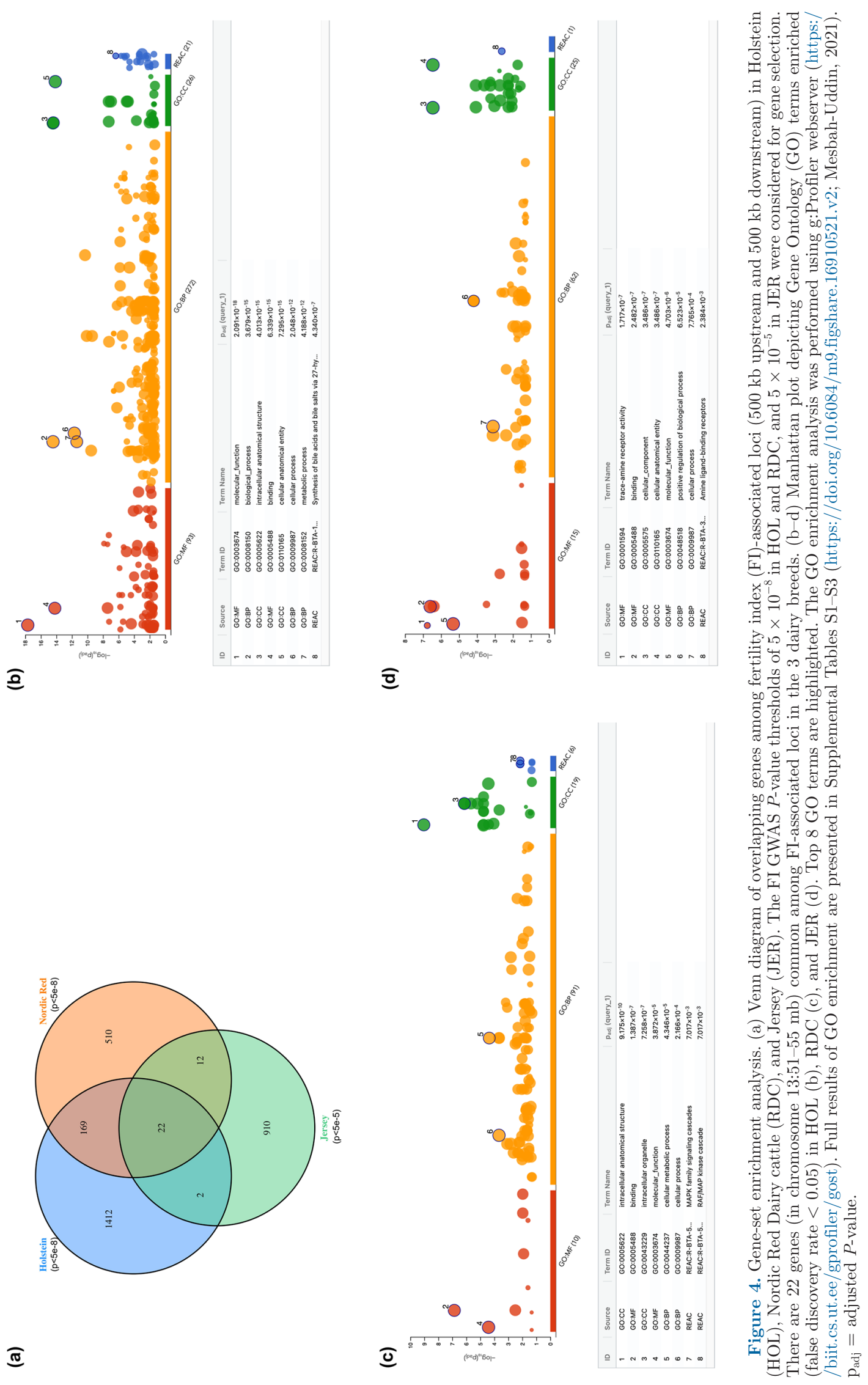


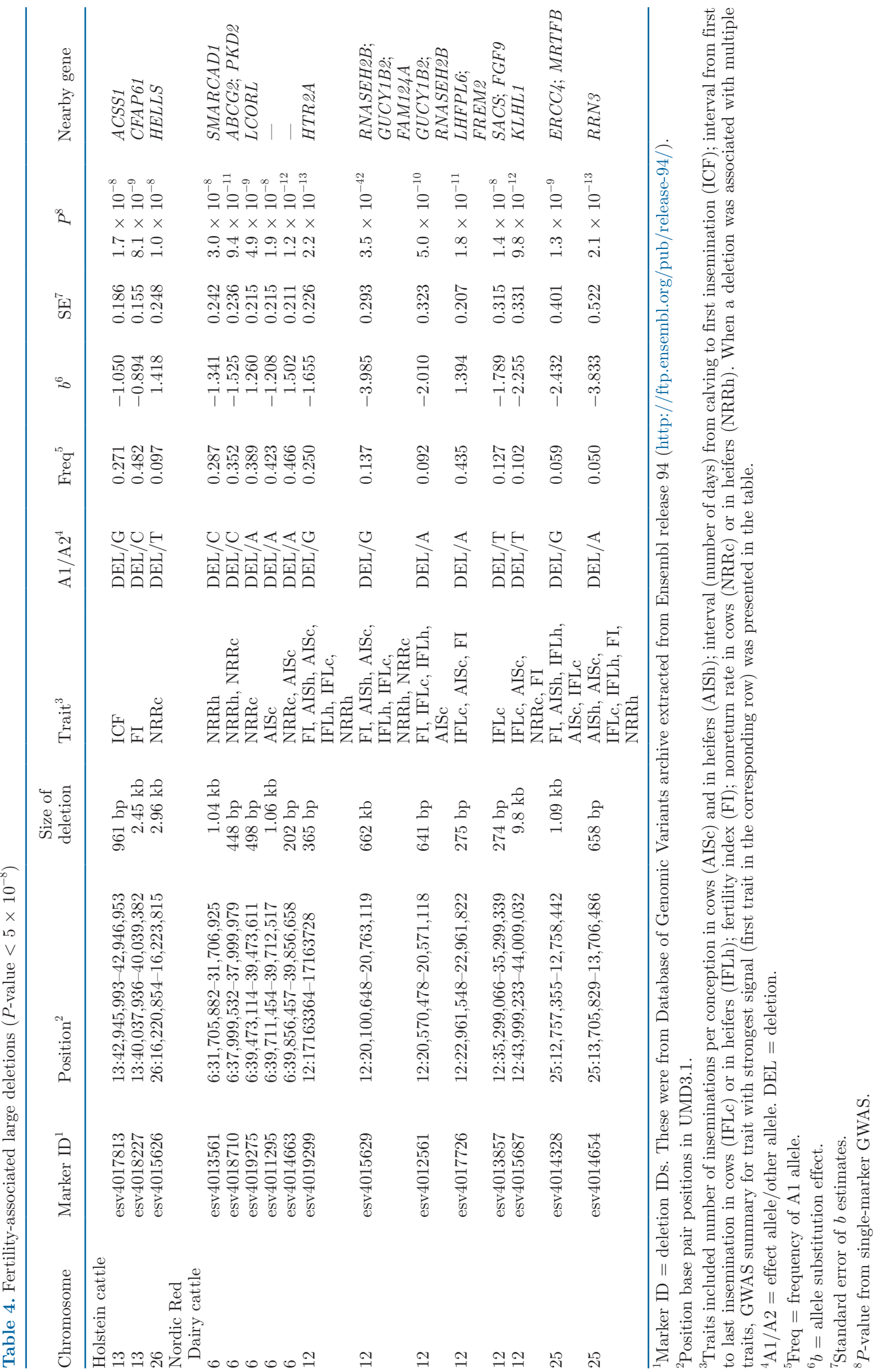


nonreturn rate in heifers, $P=1.8 \times 10^{-5}$ ). Among these 5 deletions, only esv4017388 was located within a QTL associated with NRRc (Figure 3h). Candidate genes for this locus include ADARB1 (ENSBTAG00000017486, $52 \mathrm{~kb}$ upstream of esv4017388) and POFUT2 (ENSBTAG00000007818, $467 \mathrm{~kb}$ downstream of esv4017388). In mice, homozygous mutation of $A D A R B 1$ causes postnatal lethality (entry MGI: 891999 in the Mouse Genome Informatics database, http://www.informatics .jax.org/), whereas the inactivation of POFUT2 causes embryonic lethality during organogenesis as well as lethality between implantation and somite formation (MGI: 1916863).

\section{FI-Associated SNPs and Indels}

FI-Associated Loci in HOL. In HOL, for the 8 fertility traits, 30,384 SNPs and 178 indels in total reached the significance threshold (Figure 1 and Table 2). Among these significant markers, COJO analysis identified 37 FI-associated independent loci [see Table 5 for the list of QTL and Supplemental Table S5 (https: //doi.org/10.6084/m9.figshare.16910521.v2; MesbahUddin, 2021) for candidate genes]. In addition to FI, we also performed COJO analyses for the 7 other traits and identified 217 independent loci associated with one or more of these fertility traits (Supplemental Table S6; https://doi.org/10.6084/m9.figshare.16910521.v2; Mesbah-Uddin, 2021). The top 3 FI loci in terms of significance were centered on variants rs434006863 on chromosome $13\left(P=1.5 \times 10^{-22}\right)$, rs380439408 on chromosome $24\left(P=5.4 \times 10^{-14}\right)$, and $\mathrm{rs} 380495923$ on chromosome $10\left(P=2.0 \times 10^{-12}\right)$. The candidate genes for rs434006863, rs380439408, and rs380495923 were $M P P 7, C D H 2$, and TBPL2, respectively. Homozygous mutation of $C D H 2$ causes embryonic lethality in mice [MGI: 88355], and female mice homozygous for a TBPL2 knockout allele exhibit infertility due to impaired folliculogenesis [MGI: 2684058]. For details, see Supplemental Table S5.

FI-Associated Loci in RDC. In RDC, we identified 23,481 SNPs and 189 indels with genome-wide significant associations with fertility traits (Table 2). The COJO analysis identified 23 FI-associated independent GWAS signals, 9 of which were located on chromosome 12 (Table 6). The LD pattern (correlation) of these 9 lead markers is presented in Table 7. Functional annotations of the genes located within these QTL regions (top markers and $500 \mathrm{~kb}$ of the surrounding area) are presented in Supplemental Table S7 (https: //doi.org/10.6084/m9.figshare.16910521.v2; MesbahUddin, 2021). Interestingly, the candidate genes within these loci also have known fertility-related functions in cattle, and mouse (Supplemental Table S7). Overall, the COJO analyses for the 8 traits resulted in 111 independent loci associated with either FI or different component traits (Supplemental Table S8; https://doi .org/10.6084/m9.figshare.16910521.v2; Mesbah-Uddin, 2021).

FI-Associated Loci in JER. Finally, for JER, 17 SNPs were significantly associated with either ICF, IFLc, or NRRc (Figure 3 and Table 2). After conditional analyses, we identified 2 independent GWAS loci each for ICF and NNRc, and 1 locus for IFLc (Supplemental Table S9; https://doi.org/10.6084/m9 .figshare.16910521.v2; Mesbah-Uddin, 2021). However, our GWAS was underpowered to identify FI-associated loci in JER. In an earlier study, Höglund et al. (2015b) reported 6 FI-associated QTL with $P<5.6 \times 10^{-9}$ for this JER population. The allele frequencies and the effect estimates $(\beta)$ for the Bonferroni significant FIassociated SNPs from the Höglund et al. study was perfectly correlated $(\mathrm{r}>0.99)$ with the corresponding results from this study (Supplemental Figure S1a,b; https://doi.org/10.6084/m9.figshare.16910521.v2; Mesbah-Uddin, 2021); however, on average, the $\beta$ values were 1.8 times higher in the former study (Supplemental Figure S1b). Moreover, we did not observe significant association with FI in JER, though there were suggestive signals at those loci (Supplemental Figure S1c). Two factors, namely, sample size and control for genomic inflation, could explain this situation. In JER, we had about 4 times fewer samples compared with HOL and RDC, and thus lower QTL detection power. Sample size did not differ much between Höglund et al. and our study (1,225 vs. 1,211 here). However, control of genomic inflation was much more stringent in this study with a $\lambda$ of 1.27 after correction versus 1.88 in Höglund et al. (2015b).

\section{CONCLUSIONS}

In this study, we identified several novel QTL for female fertility in Nordic dairy cattle. With our imputed data, we detected a previously observed deletion acting as a fertility QTL in RDC. Here, with imputed data, the GWAS signal for this QTL was stronger than in the previous report by Kadri et al. (2014). Few other deletions also reached the GWAS significant threshold but were not among the top signals of those loci. We hypothesize that these deletions could be potential causal variants for those loci, given that deletion of an essential gene could be lethal; however, this needs further validation. The majority of the candidate genes within the reported QTL regions had established fertility-related function in mice, illustrating the functional and biological relevance of these QTL for female fertility in dairy cattle. However, our analyses were limited 


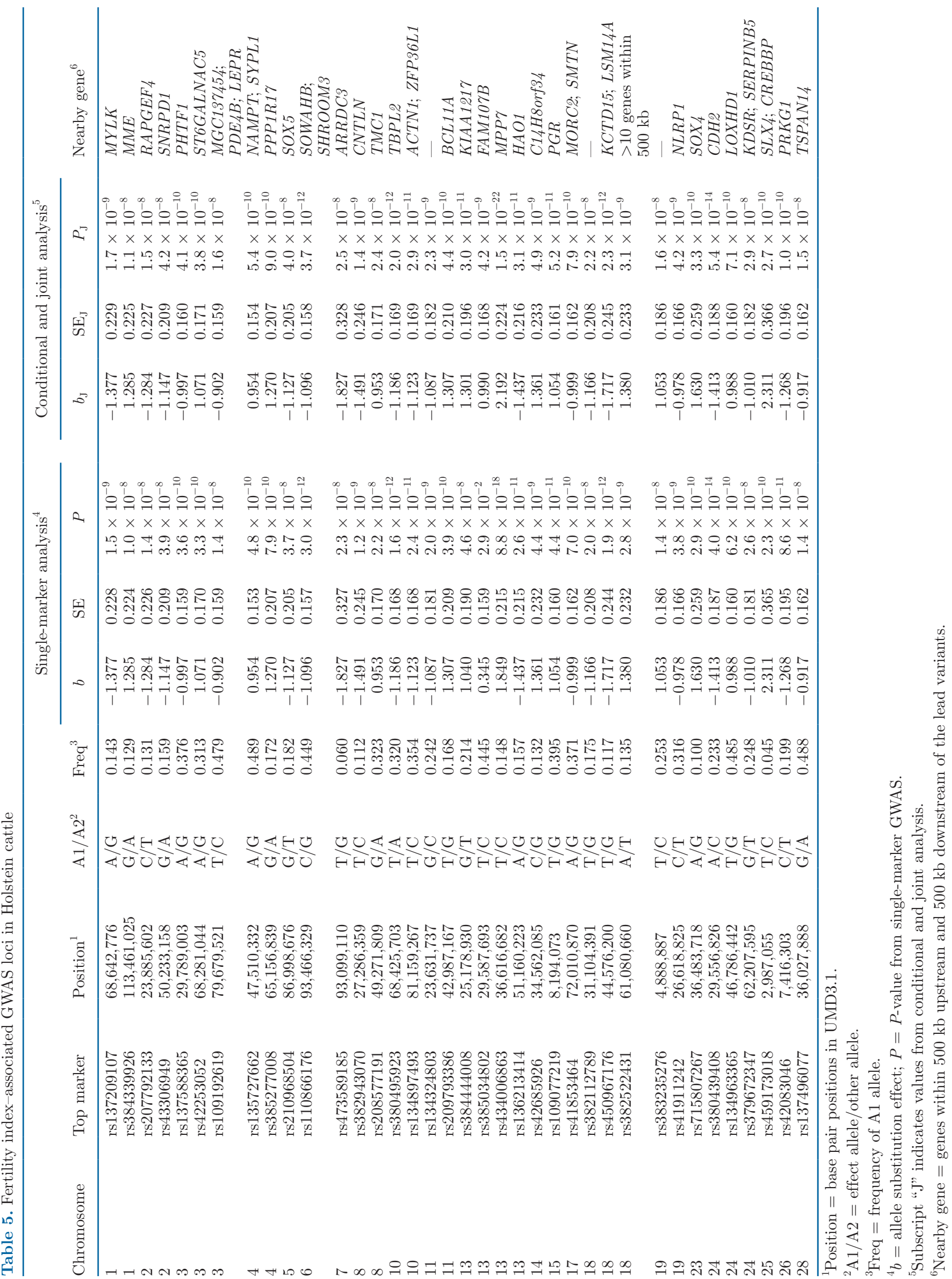




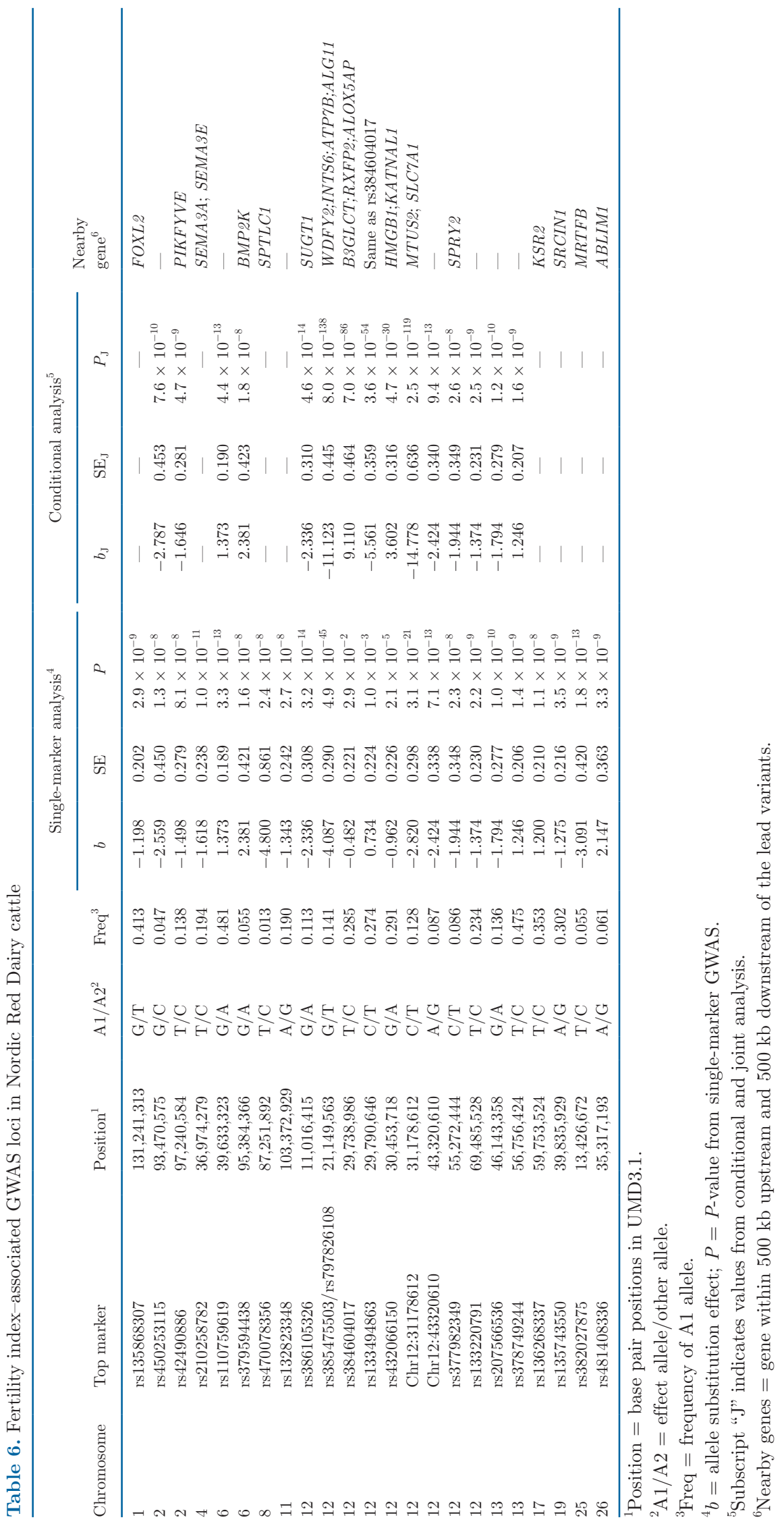




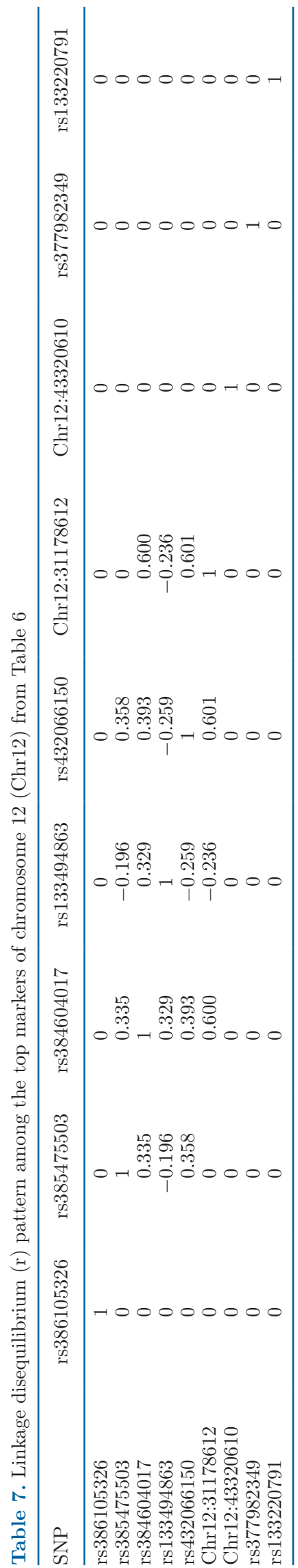

to within-breed QTL discovery, which needs replication in independent cohorts of animals. Nevertheless, QTL identified in this study will be included in future releases of the custom SNP chip used for genomic evaluations; this will enable their validation in independent populations, and subsequent studies will elucidate the effect of these markers in prediction accuracy for female fertility in dairy cattle.

\section{ACKNOWLEDGMENTS}

We are grateful to the Nordic Cattle Genetic Evaluation (NAV), Aarhus, Denmark, for providing the phenotypic data used in this study and Viking Genetics, Randers, Denmark, for providing blood and semen samples for genotyping. This research was supported by the Center for Genomic Selection in Animals and Plants (GenSAP) funded by Innovation Fund Denmark (grant 0603-00519B; Aarhus, Denmark). Md Mesbah-Uddin benefited from a joint grant from the European Commission within the framework of the Erasmus-Mundus joint doctorate "EGS-ABG." Authors also acknowledge the 1000 Bull Genomes Project and its partners for sharing genomic information. Authors are also grateful to the Genotoul bioinformatics platform Toulouse Midi-Pyrenees (Bioinfo Genotoul) for providing computing and storage resources. This study was part of Md Mesbah-Uddin's PhD thesis formally submitted to GSST, Aarhus University, Denmark, and ABIES, AgroParisTech, France. The authors have not stated any conflicts of interest.

\section{REFERENCES}

Abo-Ismail, M. K., L. F. Brito, S. P. Miller, M. Sargolzaei, D. A. Grossi, S. S. Moore, G. Plastow, P. Stothard, S. Nayeri, and F. S. Schenkel. 2017. Genome-wide association studies and genomic prediction of breeding values for calving performance and body conformation traits in Holstein cattle. Genet. Sel. Evol. 49:82. https:/ /doi.org/10.1186/s12711-017-0356-8.

Bouwman, A. C., H. D. Daetwyler, A. J. Chamberlain, C. H. Ponce, M. Sargolzaei, F. S. Schenkel, G. Sahana, A. Govignon-Gion, S. Boitard, M. Dolezal, H. Pausch, R. F. Brondum, P. J. Bowman, B. Thomsen, B. Guldbrandtsen, M. S. Lund, B. Servin, D. J. Garrick, J. Reecy, J. Vilkki, A. Bagnato, M. Wang, J. L. Hoff, R. D. Schnabel, J. F. Taylor, A. A. E. Vinkhuyzen, F. Panitz, C. Bendixen, L. E. Holm, B. Gredler, C. Hoze, M. Boussaha, M. P. Sanchez, D. Rocha, A. Capitan, T. Tribout, A. Barbat, P. Croiseau, C. Drogemuller, V. Jagannathan, C. Vander Jagt, J. J. Crowley, A. Bieber, D. C. Purfield, D. P. Berry, R. Emmerling, K. U. Gotz, M. Frischknecht, I. Russ, J. Solkner, C. P. Van Tassell, R. Fries, P. Stothard, R. F. Veerkamp, D. Boichard, M. E. Goddard, and B. J. Hayes. 2018. Meta-analysis of genome-wide association studies for cattle stature identifies common genes that regulate body size in mammals. Nat. Genet. 50:362-367. https://doi.org/10.1038/ s41588-018-0056-5.

Brøndum, R. F., B. Guldbrandtsen, G. Sahana, M. S. Lund, and G. Su. 2014. Strategies for imputation to whole genome sequence using a single or multi-breed reference population in cattle. BMC Genomics 15:728. https://doi.org/10.1186/1471-2164-15-728. 
Brøndum, R. F., G. Su, L. Janss, G. Sahana, B. Guldbrandtsen, D. Boichard, and M. S. Lund. 2015. Quantitative trait loci markers derived from whole genome sequence data increases the reliability of genomic prediction. J. Dairy Sci. 98:4107-4116. https://doi.org/ $10.3168 /$ jds.2014-9005.

Browning, B. L., and S. R. Browning. 2016. Genotype imputation with millions of reference samples. Am. J. Hum. Genet. 98:116-126. https://doi.org/10.1016/j.ajhg.2015.11.020.

Cai, Z., B. Guldbrandtsen, M. S. Lund, and G. Sahana. 2018. Prioritizing candidate genes post-GWAS using multiple sources of data for mastitis resistance in dairy cattle. BMC Genomics 19:656. https://doi.org/10.1186/s12864-018-5050-x.

Charlier, C., J. S. Agerholm, W. Coppieters, P. Karlskov-Mortensen, W. Li, G. de Jong, C. Fasquelle, L. Karim, S. Cirera, N. Cambisano, N. Ahariz, E. Mullaart, M. Georges, and M. Fredholm. 2012. A deletion in the bovine FANCI gene compromises fertility by causing fetal death and brachyspina. PLoS One 7:e43085. https:// doi.org/10.1371/journal.pone.0043085.

Chen, H., and P. C. Boutros. 2011. VennDiagram: A package for the generation of highly-customizable Venn and Euler diagrams in $\mathrm{R}$. BMC Bioinformatics 12:35. https://doi.org/10.1186/1471-2105-12 -35 .

Daetwyler, H. D., A. Capitan, H. Pausch, P. Stothard, R. van Binsbergen, R. F. Brondum, X. Liao, A. Djari, S. C. Rodriguez, C. Grohs, D. Esquerre, O. Bouchez, M. N. Rossignol, C. Klopp, D. Rocha, S. Fritz, A. Eggen, P. J. Bowman, D. Coote, A. J. Chamberlain, C. Anderson, C. P. VanTassell, I. Hulsegge, M. E. Goddard, B. Guldbrandtsen, M. S. Lund, R. F. Veerkamp, D. A. Boichard, R. Fries, and B. J. Hayes. 2014. Whole-genome sequencing of 234 bulls facilitates mapping of monogenic and complex traits in cattle. Nat. Genet. 46:858-865. https://doi.org/10.1038/ng.3034.

Das, S., L. Forer, S. Schonherr, C. Sidore, A. E. Locke, A. Kwong, S. I. Vrieze, E. Y. Chew, S. Levy, M. McGue, D. Schlessinger, D. Stambolian, P. R. Loh, W. G. Iacono, A. Swaroop, L. J. Scott, F. Cucca, F. Kronenberg, M. Boehnke, G. R. Abecasis, and C. Fuchsberger. 2016. Next-generation genotype imputation service and methods. Nat. Genet. 48:1284-1287. https://doi.org/10.1038/ ng.3656.

de Roos, A. P., B. J. Hayes, R. J. Spelman, and M. E. Goddard. 2008. Linkage disequilibrium and persistence of phase in HolsteinFriesian, Jersey and Angus cattle. Genetics 179:1503-1512. https: //doi.org/10.1534/genetics.107.084301.

Delaneau, O., B. Howie, A. J. Cox, J. F. Zagury, and J. Marchini. 2013. Haplotype estimation using sequencing reads. Am. J. Hum. Genet. 93:687-696. https://doi.org/10.1016/j.ajhg.2013.09.002.

Delaneau, O., J. Marchini, and 1000 Genomes Project Consortium. 2014. Integrating sequence and array data to create an improved 1000 Genomes Project haplotype reference panel. Nat. Commun. 5:3934. https://doi.org/10.1038/ncomms4934.

Elsik, C. G., D. R. Unni, C. M. Diesh, A. Tayal, M. L. Emery, H. N. Nguyen, and D. E. Hagen. 2016. Bovine Genome Database: New tools for gleaning function from the Bos taurus genome. Nucleic Acids Res. 44(D1):D834-D839. https://doi.org/10.1093/nar/ gkv1077.

Garrick, D. J., J. F. Taylor, and R. L. Fernando. 2009. Deregressing estimated breeding values and weighting information for genomic regression analyses. Genet. Sel. Evol. 41:55. https://doi.org/10 $.1186 / 1297-9686-41-55$.

Gebreyesus, G., A. J. Buitenhuis, N. A. Poulsen, M. Visker, Q. Zhang, H. J. F. van Valenberg, D. Sun, and H. Bovenhuis. 2019. Multipopulation GWAS and enrichment analyses reveal novel genomic regions and promising candidate genes underlying bovine milk fatty acid composition. BMC Genomics 20:178. https://doi.org/10 $.1186 / \mathrm{s} 12864-019-5573-9$.

Handsaker, R. E., J. M. Korn, J. Nemesh, and S. A. McCarroll. 2011. Discovery and genotyping of genome structural polymorphism by sequencing on a population scale. Nat. Genet. 43:269-276. https:/ /doi.org/10.1038/ng.768.

Höglund, J. K., B. Buitenhuis, B. Guldbrandtsen, M. S. Lund, and G. Sahana. 2015a. Genome-wide association study for female fertil- ity in Nordic Red cattle. BMC Genet. 16:110. https://doi.org/10 $.1186 / \mathrm{s} 12863-015-0269-\mathrm{x}$.

Höglund, J. K., B. Guldbrandtsen, M. S. Lund, and G. Sahana. 2015b. Identification of genomic regions associated with female fertility in Danish Jersey using whole genome sequence data. BMC Genet. 16:60. https://doi.org/10.1186/s12863-015-0210-3.

Höglund, J. K., G. Sahana, B. Guldbrandtsen, and M. S. Lund. 2014. Validation of associations for female fertility traits in Nordic Holstein, Nordic Red and Jersey dairy cattle. BMC Genet. 15:8. https: //doi.org/10.1186/1471-2156-15-8.

Hu, Z. L., C. A. Park, and J. M. Reecy. 2016. Developmental progress and current status of the Animal QTLdb. Nucleic Acids Res. 44(D1):D827-D833. https://doi.org/10.1093/nar/gkv1233.

Iso-Touru, T., G. Sahana, B. Guldbrandtsen, M. S. Lund, and J. Vilkki. 2016. Genome-wide association analysis of milk yield traits in Nordic Red Cattle using imputed whole genome sequence variants. BMC Genet. 17:55. https://doi.org/10.1186/s12863-016-0363-8.

Jardim, J. G., B. Guldbrandtsen, M. S. Lund, and G. Sahana. 2018. Association analysis for udder index and milking speed with imputed whole-genome sequence variants in Nordic Holstein cattle. J. Dairy Sci. 101:2199-2212. https://doi.org/10.3168/jds.2017-12982.

Jiang, L., Z. Zheng, T. Qi, K. E. Kemper, N. R. Wray, P. M. Visscher, and J. Yang. 2019. A resource-efficient tool for mixed model association analysis of large-scale data. Nat. Genet. 51:1749-1755. https://doi.org/10.1038/s41588-019-0530-8.

Kadri, N. K., B. Guldbrandtsen, M. S. Lund, and G. Sahana. 2015. Genetic dissection of milk yield traits and mastitis resistance quantitative trait loci on chromosome 20 in dairy cattle. J. Dairy Sci. 98:9015-9025. https://doi.org/10.3168/jds.2015-9599.

Kadri, N. K., G. Sahana, C. Charlier, T. Iso-Touru, B. Guldbrandtsen, L. Karim, U. S. Nielsen, F. Panitz, G. P. Aamand, N. Schulman, M. Georges, J. Vilkki, M. S. Lund, and T. Druet. 2014. A 660-Kb deletion with antagonistic effects on fertility and milk production segregates at high frequency in Nordic Red cattle: additional evidence for the common occurrence of balancing selection in livestock. PLoS Genet. 10:e1004049. https://doi.org/10.1371/journal .pgen.1004049.

Li, H., B. Handsaker, A. Wysoker, T. Fennell, J. Ruan, N. Homer, G. Marth, G. Abecasis, R. Durbin, and 1000 Genome Project Data Processing Subgroup. 2009. The Sequence Alignment/Map format and SAMtools. Bioinformatics 25:2078-2079. https://doi.org/10 $.1093 /$ bioinformatics/btp352.

Liu, S., J. Zhang, Z. E. Kherraf, S. Sun, X. Zhang, C. Cazin, C. Coutton, R. Zouari, S. Zhao, F. Hu, S. F. B. Mustapha, C. Arnoult, P. F. Ray, and M. Liu. 2021. CFAP61 is required for sperm flagellum formation and male fertility in human and mouse. bioRxiv:2021 .2003 .2004 .433881 .

Marete, A., G. Sahana, S. Fritz, R. Lefebvre, A. Barbat, M. S. Lund, B. Guldbrandtsen, and D. Boichard. 2018. Genome-wide association study for milking speed in French Holstein cows. J. Dairy Sci. 101:6205-6219. https://doi.org/10.3168/jds.2017-14067.

McKenna, A., M. Hanna, E. Banks, A. Sivachenko, K. Cibulskis, A. Kernytsky, K. Garimella, D. Altshuler, S. Gabriel, M. Daly, and M. A. DePristo. 2010. The Genome Analysis Toolkit: a MapReduce framework for analyzing next-generation DNA sequencing data. Genome Res. 20:1297-1303. https://doi.org/10.1101/gr .107524 .110 .

Mesbah-Uddin, M. 2021. Supplementary Table S1-9. Figshare. Dataset. https://doi.org/https://doi.org/10.6084/m9.figshare.16910521 .v1.

Mesbah-Uddin, M., B. Guldbrandtsen, T. Iso-Touru, J. Vilkki, D. J. De Koning, D. Boichard, M. S. Lund, and G. Sahana. 2018. Genome-wide mapping of large deletions and their population-genetic properties in dairy cattle. DNA Res. 25:49-59. https://doi.org/10 $.1093 /$ dnares/dsx037.

Mesbah-Uddin, M., B. Guldbrandtsen, M. S. Lund, D. Boichard, and G. Sahana. 2019. Joint imputation of whole-genome sequence variants and large chromosomal deletions in cattle. J. Dairy Sci. 102:11193-11206. https://doi.org/10.3168/jds.2019-16946. 
NAV. 2013. Fertility. Pages 27-32 in NAV Routine Genetic Evaluation of Dairy Cattle - Data and Genetic Models. 2nd ed. Nordic Cattle Genetic Evaluation.

Raudvere, U., L. Kolberg, I. Kuzmin, T. Arak, P. Adler, H. Peterson, and J. Vilo. 2019. g:Profiler: A web server for functional enrichment analysis and conversions of gene lists (2019 update). Nucleic Acids Res. 47(W1):W191-W198. https://doi.org/10.1093/nar/ gkz369.

Sahana, G., T. Iso-Touru, X. Wu, U. S. Nielsen, D. J. de Koning, M. S. Lund, J. Vilkki, and B. Guldbrandtsen. 2016. A 0.5-Mbp deletion on bovine chromosome 23 is a strong candidate for stillbirth in Nordic Red cattle. Genet. Sel. Evol. 48:35. https://doi.org/10 .1186/s12711-016-0215-z.

Sanchez, M. P., Y. Ramayo-Caldas, V. Wolf, C. Laithier, M. El Jabri, A. Michenet, M. Boussaha, S. Taussat, S. Fritz, A. DelacroixBuchet, M. Brochard, and D. Boichard. 2019. Sequence-based GWAS, network and pathway analyses reveal genes co-associated with milk cheese-making properties and milk composition in Montbeliarde cows. Genet. Sel. Evol. 51:34. https://doi.org/10.1186/ s12711-019-0473-7.

Turner, S. D. 2018. qqman: An R package for visualizing GWAS results using Q-Q and Manhattan plots. J. Open Source Softw. 3:731. https://doi.org/10.21105/joss.00731.

van den Berg, I., D. Boichard, B. Guldbrandtsen, and M. S. Lund. 2016. Using sequence variants in linkage disequilibrium with causative mutations to improve across-breed prediction in dairy cattle: A simulation study. G3 (Bethesda) 6:2553-2561. https://doi.org/ 10.1534/g3.116.027730.

VanRaden, P. M., and G. R. Wiggans. 1991. Derivation, calculation, and use of national animal model information. J. Dairy Sci. 74:2737-2746. https://doi.org/10.3168/jds.S0022-0302(91)78453 $-1$.

Yang, J., T. Ferreira, and A. P. Morris. 2012. Conditional and joint multiple-SNP analysis of GWAS summary statistics identifies additional variants influencing complex traits. Nat. Genet. 44:369375. https://doi.org/10.1038/ng.2213.

Yang, J., S. H. Lee, M. E. Goddard, and P. M. Visscher. 2011a. GCTA: A tool for genome-wide complex trait analysis. Am. J. Hum. Genet. 88:76-82. https://doi.org/10.1016/j.ajhg.2010.11.011.
Yang, J., M. N. Weedon, S. Purcell, G. Lettre, K. Estrada, C. J. Willer, A. V. Smith, E. Ingelsson, J. R. O'Connell, M. Mangino, R. Magi, P. A. Madden, A. C. Heath, D. R. Nyholt, N. G. Martin, G. W. Montgomery, T. M. Frayling, J. N. Hirschhorn, M. I. McCarthy, M. E. Goddard, P. M. Visscher, and G. Consortium. 2011b. Genomic inflation factors under polygenic inheritance. Eur. J. Hum. Genet. 19:807-812. https://doi.org/10.1038/ejhg.2011.39.

Zerbino, D. R., P. Achuthan, W. Akanni, M. R. Amode, D. Barrell, J. Bhai, K. Billis, C. Cummins, A. Gall, C. G. Giron, L. Gil, L. Gordon, L. Haggerty, E. Haskell, T. Hourlier, O. G. Izuogu, S. H. Janacek, T. Juettemann, J. K. To, M. R. Laird, I. Lavidas, Z. Liu, J. E. Loveland, T. Maurel, W. McLaren, B. Moore, J. Mudge, D. N. Murphy, V. Newman, M. Nuhn, D. Ogeh, C. K. Ong, A. Parker, M. Patricio, H. S. Riat, H. Schuilenburg, D. Sheppard, H. Sparrow, K. Taylor, A. Thormann, A. Vullo, B. Walts, A. Zadissa, A. Frankish, S. E. Hunt, M. Kostadima, N. Langridge, F. J. Martin, M. Muffato, E. Perry, M. Ruffier, D. M. Staines, S. J. Trevanion, B. L. Aken, F. Cunningham, A. Yates, and P. Flicek. 2018. Ensembl 2018. Nucleic Acids Res. 46(D1):D754-D761. https://doi.org/10 .1093/nar/gkx1098.

Zimin, A. V., A. L. Delcher, L. Florea, D. R. Kelley, M. C. Schatz, D. Puiu, F. Hanrahan, G. Pertea, C. P. Van Tassell, T. S. Sonstegard, G. Marcais, M. Roberts, P. Subramanian, J. A. Yorke, and S. L. Salzberg. 2009. A whole-genome assembly of the domestic cow, Bos taurus. Genome Biol. 10:R42. https://doi.org/10.1186/ gb-2009-10-4-r42.

\section{ORCIDS}

Md Mesbah-Uddin @ https://orcid.org/0000-0003-1846-0411 Bernt Guldbrandtsen ำ https://orcid.org/0000-0003-1764-135X Aurélien Capitan ํ https://orcid.org/0000-0003-3185-0932 Didier Boichard ๑ https://orcid.org/0000-0003-0361-2961 Goutam Sahana @ https://orcid.org/0000-0001-7608-7577 